\title{
REPERTORIO BIBLIOGRÁFICO SOBRE EL RÉGIMEN POLÍTICO CHILENO (III)
}

CAYETANO NÚÑEZ RIVERO

\author{
y \\ JOSÉ DÍAZ NIEVA
}





\title{
REPERTORIO BIBLIOGRÁFICO SOBRE EL RÉGIMEN POLÍTICO CHILENO (III)
}

\author{
POR \\ CAYETANO NÚÑEZ RIVERO \\ Profesor Titular de Derecho Político \\ UNED \\ JOSÉ DÍAZ NIEVA \\ Profesor de Ciencia Política \\ Universidad Bernardo O’Higgins
}

\subsection{El radicalismo y el Frente Popular}

Angell, Alan: "Chile: el primer fracaso del Frente Popular», Historia 16, n.

6, Madrid, octubre 1976.

ARgos: El radicalismo chileno, Imp. Franklin, Santiago de Chile, 1875.

Baltra, Alberto: Pedro Aguirre Cerda, Ed. Orbe, Santiago de Chile, 1960.

BARRIA Soto, Francisco: El Partido Radical, su historia y sus obras, Ed. Universitaria, Santiago de Chile, 1957.

Bravo, Alfredo Guillermo: El Partido Radical y el Frente Popular, La República, Santiago de Chile, 1936.

Cabero, Alberto: Recuerdos de Don Pedro Aguirre Cerda, Ed. Nascimiento, Santiago de Chile, 1948.

Carvallo, Ramón Liborio: Ojeada histórica sobre el Partido Radical, Santiago de Chile, 1909. 
CIEDES: El Partido Radical: antecedentes históricos y Perspectivas futuras, CIEDES, Santiago de Chile, 1988.

Democracia Radical: Declaración de principios y estatutos, Imp. El Imparcial, Santiago de Chile, 1969.

Duran Bernales, Florencio: El Partido Radical, Ed. Nascimiento, Santiago de Chile, 1958.

Durán Neuman, Julio: Rectificaciones urgentes en una hora de angustia, Santiago de Chile, 1961.

EsPeJo, Ángel Custodio: El Partido Radical, sus obras, sus hombres, Imp. Santiago, Santiago de Chile, 1911.

Fernández, J. F.: Pedro Aguirre Cerda y el Frente Popular, Ed. Ercilla, Santiago de Chile, 1938.

Frente Popular: Programa del Frente Popular, Santiago de Chile, 1936.

GaLDAMES, Luis: Valentín Letelier y su obra, Imp. Universitaria, Santiago de Chile, 1937.

Garcia Covarrubias, Jaime: El Partido Radical y la clase media (la relación de intereses entre 1888 y 1938), Ed. Andrés Bello, Santiago de Chile, 1990.

- "El Partido Radical y su relación de intereses con la clase media en Chile en el período 1888-1938", Política, n. 12, Santiago de Chile, julio 1987.

GonzÁlez VIDELA, Gabriel: El Partido Radical y la evolución social de Chile, Santiago de Chile, 1938.

- Memorias, Ed. Gabriela Mistral, Santiago de Chile, 1975.

- Responsabilidad del radicalismo como partido de gobierno, s/e, s/l, s/f.

Guzmán Hernández, J.: Gabriel González Videla. Biografía, análisis crítico de su programa, Imp. Universo, Santiago de Chile, 1946.

Herring, Hubert: Chile en la Presidencia de Don Pedro Aguirre Cerda, Ed. Francisco de Aguirre, Buenos Aires, 1979.

Hormaechea Reyes, Armando: El Frente Popular de 1938, Ed. Universitaria, Santiago de Chile, 1938. 
Kopplin laÁ̃̃EZ, Arnoldo: «El Partido Radical a través de sus Convenciones 1931-1934. Notas para un estudio", Tesis de Licenciatura, Santiago de Chile, 1984.

Koscina Peralta, Yerko: El radicalismo como partido político, Ed. Universitaria, Santiago de Chile, 1956.

Labra Carvajal, Armando: La política radical, Santiago de Chile, 1915.

MAC-IVER, Enrique: Discursos políticos y parlamentarios. 1868-1898, Santiago de Chile, 1899.

Muñoz Delaunoy, Ignacio: Historia del poder: La Sociedad Nacional de Agricultura durante el período del Frente Popular, Fund. Mario Góngora, Santiago de Chile, 1992.

Olavarría Alarcón, Simeón: La gran culpa del Partido Radical, Imp. Victoria, Santiago de Chile, 1946.

Olavarria Bravo, Arturo: Carta dirigida a los radicales del pais, Artes y Letras Impresores, Santiago de Chile, 1942.

- Casos y cosas de la política, Imp. Stanley, Santiago de Chile, 1950.

- Chile entre dos Alessandri. Memorias políticas, Ed. Nascimiento, Santiago de Chile, 1962.

OpIrz, Pedro: Acción del Partido Radical frente a los problemas nacionales, Imp. El Imparcial, Santiago de Chile, 1937.

Oyarzun, Enrique: El radicalismo ante la revolución actual, Imp. Central, Santiago de Chile, 1925.

Palma ZúNiga, Luis: Historia del Partido Radical, Ed. Andrés Bello, Santiago de Chile, 1967.

- Pedro Aguirre Cerda. Maestro, estadista y gobernante, Ed. Andrés BeIlo, Santiago de Chile, 1963.

Palma Zúñiga, Luis, e Iglesias Meléndez, Julio: Presidencia de Juan Antonio Ríos, Ed. Universitaria, Santiago de Chile, s/f.

Partido de Izouierda Radical: Bases ideológicas y declaración de principios, Santiago de Chile, 1971.

- El retiro del Gobierno y de la Unidad Popular. Los principales documentos, declaraciones y comentarios sobre el retiro del PIR, Santiago de Chile, 1972. 
- La Izquierda Radical y la realidad política nacional. Principios básicos de la Izquierda Radical, Ed. por la comp. política del PIR, Santiago de Chile, 1972.

- Trayectoria política del PIR. Gestión, doctrina, fundación, acción parlamentaria, gobierno, retiro, oposición, Imp. Los Andes, Santiago de Chile, 1972.

PARTIDo Radical: Antecedentes históricos y programáticos. Perspectivas de futuro, Santiago de Chile, 1987.

- Declaración de principios del radicalismo, Ed. Lautaro, Santiago de Chile, 1953.

- El radicalismo en el orden del día de Pedro Aguirre Cerda, Frente Popular 1933 a Salvador Allende, Unidad Popular 1970, Imp. Neupert, Santiago de Chile, 1970.

- En defensa de los principios, Santiago de Chile, 1946.

- Estatutos, programas, Imp. Artes y Letras, Santiago de Chile, 1921.

- Principios y programas en que inspirará su acción de gobernante Julio Durán, Imp. Entrecerros, Santiago de Chile, 1964.

- Programa de la Convención Radical de 1888, Imp. La Libertad Electoral, Santiago de Chile, 1889.

- Programa del Partido Radical aprobado por la 5. ${ }^{a}$ Convención de Concepción, 14-17 de noviembre de 1919, Ed. Numen, Santiago de Chile, 1919.

- Programa, estatutos, reglamentos, Santiago de Chile, 1934.

- "Catorce Propuestas del Partido Radical», Ed. Melquíades, Santiago de Chile, 1988.

Partido Radical Doctrinario: Declaración de principios y estatutos, aprobados en el Pleno Nacional celebrado los días 13 y 14 de junio de 1953.

Partido Social Demócrata: Declaración de principios, Santiago de Chile, s/f (¿1968?).

Petras, James: El radicalismo político de la clase obrera chilena, Centro Ed. de América Latina, Buenos Aires, s/f.

Poblete Núñez, Darío: Historia del Partido Radical, La República, Santiago de Chile, 1936. 
Poblete, Darío, y Bravo, Alfonso: Historia del Partido Radical y el Frente Popular, Imp. La República, Santiago de Chile, 1936.

Podlech Davison, Jorge: Panorama político del momento. El frentismo ante el Partido Radical, Santiago de Chile, 1936.

QuinzIo FigueIRedo, Jorge Mario: El Partido Radical, origen, doctrina y convenciones, Ed. Bocanegra, Santiago de Chile, 1964.

Retting, Raúl: "En defensa de la doctrina radical», Ed. Continente, 1944.

ReYes Álvarez, Jaime: «Los presidentes radicales y su partido. Chile 19381952", CEP (Documento de trabajo), Santiago de Chile, 1989.

Rios, Juan Antonio: Durante el gobierno del General lbáñez. Actuación de la Junta Central Radical, Santiago de Chile, 1931.

Snow, Peter: Radicalismo chileno, Ed. Fco. de Aguirre, Santiago de Chile, 1972.

Stevenson, John R.: The Chilean Popular Front, University of Pennsylvania Press, Philadelphia, 1942.

Urzua V., Germán: El Partido Radical, su evolución política, Academia de Ciencias Políticas y Administrativas, Santiago de Chile, 1961.

Vera Riquelme, Enrique: Evolución del radicalismo chileno, Santiago de Chile, 1943.

VIVANCo, Alejandro: El radicalismo: su evolución constructiva, La Nación, Santiago de Chile, 1949.

Yopo, Boris: "Los Partidos Radical y Socialista y los Estados Unidos: 1947-1958", FLACSO (Documento de trabajo), Santiago de Chile, 1985.

\subsection{Partido Demócrata o Democrático}

Álvarez Álvarez, Héctor: Democracia. Aporte a la Convención del 20 de noviembre de 1924, Talcahuano, 1924.

- Organización funcional del Partido Democrático de Chile a base de ciudadanos con personalidad moral y de asociaciones afiliadas a su credo, s/e, Santiago de Chile, 1948. 
Bañados, Guillermo: Convención extraordinaria del Partido Demócrata, Imp. La Universal, Santiago de Chile, 1922.

Concha, Malaquías: El programa de la democracia, Imp. El Siglo XX, Santiago de Chile, 1905.

Godoy, Óscar Alfonso: Don Malaquías Concha. Su vida, sus obras, su glorificación, Imp. Bellavista, Santiago de Chile, 1923.

Grez Toso, Sergio: "Los primeros tiempos del Partido Democrático chileno (1887-1891)", en Dimensión Histórica de Chile, n. 8, Santiago de Chile, 1991.

Partido Demócrata: «Programa del Partido Democrático. Aprobado en Junta General en 20 de noviembre de 1887", en El Ferrocarril, Santiago de Chile, 29 de noviembre de 1887.

- Programa y reglamento del Partido Demócrata aprobados por la Convención de Santiago en 14 de julio de 1889, Centro Editorial de La Prensa, Santiago de Chile, 1889.

Petris Giesen, Héctor de: Historia del Partido Democrático. Posición dentro de la evolución política nacional, Imp. de la Dirección General de Prisiones, Santiago de Chile, 1942.

TURRI CONCHA, Enrique: Malaquías Concha, el político, Ed. Universitaria, Santiago de Chile, 1958.

\subsection{El Socialismo chileno y la Unidad PoPular}

Alburqueroue, Mario, y otros: "Propuestas socialistas para un Chile posiblen, Eds. de autores, Santiago de Chile, 1988.

AlLENDE, M. I Isabel: La Internacional Socialista y América Latina: pasado y presente de una relación, ILET, Santiago de Chile, 1983.

Allende, Salvador: América Latina: pueblo continente, Centro de Estudios Latinoamericanos Salvador Allende (UNAM), Puebla, 1986.

- "Carta del Presidente de Chile, Dr. Salvador Allende, a los Jefes de los Partidos de la Unidad Popular", en Revista de la Universidad Técnica del Estado, Santiago de Chile, 1972.

- Discursos, Ed. Ciencias Sociales, La Habana, 1975. 
- La realidad medio-social en Chile, Imp. Latthorng, Santiago de Chile, 1939.

- La revolución chilena, Eudeba, Buenos Aires, 1973.

- La vía chilena al socialismo, Ed. Fundamentos, Madrid, 1971.

- Las contradicciones de Chile, s/e, Santiago de Chile, 1943.

- Nuestro camino al socialismo. La vía chilena, Papiro, Buenos Aires, 1976.

AlmeYda, Clodomiro: Chile más allá de la memoria, UNAM, México, 1986.

- "El proceso de recuperación democrática en Chile», en Revista Crítica, n. 30-31, Universidad Autónoma de Puebla, Puebla, 1987.

- "El socialismo chileno y la reforma agraria", en Arauco, n. 30 , Santiago de Chile, julio de 1962.

- "Los socialistas y los cristianos", en Chile-América, n. 46-47, Roma, 1978.

- Pensando en Chile, Ed. Terranova, Santiago de Chile, 1986.

- Sociologismo e ideologismo en la teoría revolucionaria, FCE, México, 1976.

ALMEYDA, Clodomiro, y otros: "Crisis y renovación", Ed. Medusa, Santiago de Chile, 1990.

Altamirano, Carlos: Decisión revolucionaria, Ed. Quimantú, Santiago de Chile, 1973.

- Dialéctica de una derrota, Ed. Siglo XXI, México, 1977.

- El Partido Socialista y la revolución chilena, Prensa Latinoamericana, Santiago de Chile, s/f.

- «Premisas de una estrategia socialista para Chile», Berlín, 1978.

- Una Propuesta socialista para Chile, Ed. del Partido Socialista de Chile, México, 1979.

Álvarez Villablanca, Agustín: Objetivos del socialismo en Chile, Santiago de Chile, 1946.

Ampuero Díaz, Raúl: El pueblo en la defensa nacional, Prensa Latinoamericana, Santiago de Chile, 1971. 
- En defensa del Partido y del socialismo, Imp. Victoria, Santiago de Chile, 1948.

- y otros: Historia documental del Partido Socialista de Chile 1933-1983, Centro de Estudios del Movimiento Obrero Salvador Allende, Universidad Autónoma de Guerrero, Chilpancingo, 1983.

- La izquierda en punto muerto, Ed. Orbe, Santiago de Chile, 1969.

- La juventud socialista en el frente del pueblo, s/e, Santiago de Chile, 1939.

ANóNIMO: "Acción e historia del socialismo chileno", en Combate, San José de Costa Rica, septiembre-octubre, 1960.

Angelt, Alan: "Allende's first year in Chile", Current History, n.․ 62, Philadelphia, febrero 1972.

Arguedas, Sol: "Hacia el socialismo», Cuadernos Americanos, México, 1973.

ArRate, Jorge: "Apuntes para una autocrítica: la izquierda y las Fuerzas Armadas", en Chile-América, n. 33-34, Roma, julio-agosto 1977.

- El socialismo chileno: rescate y renovación, Instituto para el Nuevo Chile, Rotterdam, 1983.

- y otros: Siete ensayos sobre democracia y socialismo, Ed. Vector, Santiago de Chile, 1986.

Arriagada Herrera, Genaro: De la vía chilena a la vía insurreccional, Ed. del Pacífico, Santiago de Chile, 1974.

Artigues, Javier, y Arizo, José: «El futuro del socialismo chileno», en Ciudad Futura, n.ำ 4, Buenos Aires, 1987.

Baltra CoRTÉs, Alberto: "Gestión económica del gobierno de la Unidad Popular", Ed. Orbe, Santiago de Chile 1974.

Barrera, Manuel: Chile 1970-73. La conflictiva experiencia de los cambios estructurales, ILDIS, Caracas, 1973.

BAscuñán, Carlos: La izquierda sin Allende, Ed. Planeta, Santiago de Chile, 1990.

BAsso, Leio, y otros: Transición al socialismo, experiencia chilena, CESOCEREN-PLIA, Santiago de Chile, 1972. 
Blanco, Hugo, y otros: "La tragedia Chilena", Ed. Pluma, Buenos Aires, 1973.

Beloya, Manuel: Grove, su vida, su ejemplo, su obra, Santiago de Chile, 1964.

Benavente Urbina, Andrés: "Renovación socialista, un mito contemporáneo", en Política, Santiago de Chile, 1984.

- "Convergencia socialista: afirmaciones, contradicciones y perspectivas", ICHEH (Documento de trabajo), Santiago de Chile, 1983.

Benavides, Leopoldo: «Democratización y el desarrollo en el proyecto popular", FLACSO (Documento de trabajo), Santiago de Chile, 1982.

- La formación de la izquierda chilena: relaciones entre el Partido Socialista y el Partido Comunista, FLACSO, Santiago de Chile, 1988.

BITAR, Sergio: Transición, socialismo y democracia. La experiencia chilena, Ed. Siglo XXI, México, 1979.

BoizARD, Ricardo: El último día de Allende, Ed. del Pacífico, Santiago de Chile, 1973.

BOorsteIN, Edward: Allende's Chile, International Publishers, New York, 1977.

Borón, Atilio: "Movilización política y crisis política en Chile», en Aportes, n. 9 20, París, abril 1971.

Bossle, Lothar: Allende y el socialismo europeo, Ed. Andrés Bello, Santiago de Chile, 1979.

Campos, Enrique: "Chile viene al marxismo", en Portada, Santiago de Chile, 1972.

Caninuante, Gustavo: Los partidos políticos. La revolución chilena, Ed. Nascimiento, Santiago de Chile, 1971.

Casanueva, Fdo., y Fernández, Manuel: El Partido Socialista y la lucha de clases en Chile, Ed. Quimantú, Santiago de Chile, 1973.

Castillo, René, y otros: Los mil días de la revolución, Ed. Paz y Socialismo, Praga, 1978.

CAStro, Fidel: Discursos: Fidel en Chile, Ed. Quimantú, Santiago de Chile, 1972. 
CAStro, Juan: Conciencia socialista, Antofagasta, 1939.

Cora, M." Manuela de: "Año y medio de socialismo en Chile", en Índice, n.. 311, Madrid, julio, 1972.

Corbalán, Salomón: El Partido Socialista, Imp. Atenea, Santiago de Chile, 1957.

- Historia documental del Partido Socialista de Chile 1933-1983, Centro de Estudios del Movimiento Obrero Salvador Allende, Universidad Autónoma de Guerrero, Chilpancingo, 1983.

Corkill, David R.: "The Chilean Socialist Party and Popular Frent 1933-41", Journal of Contemporary History, n. 11, London, julio 1976.

Cuevas Farrén, Gustavo: "El proyecto histórico de la Unidad Popular», en Política, n. 15, Santiago de Chile, 1988.

Charlín, Carlos: Del avión rojo a la República Socialista, Ed. Quimantú, Santiago de Chile, 1972.

Chelén Rojas, Alejandro: El Partido de la victoria, Imp. Avance, Chaneral, 1939.

- "El Partido Socialista de Chile», en Arauco, n. ${ }^{\circ} 40$, Santiago de Chile, 1963.

- Flujo y reflujo del socialismo chileno, Ed. Combate, Santiago de Chile, 1961.

- Trayectoria del socialismo (Apuntes para una historia crítica del socialismo chileno), Ed. Austral, Buenos Aires, 1967.

CHONCHOL, Jacques, y otros: América Latina: socialismo, democracia y reforma agraria, CEDEAL, San José de Costa Rica, 1981.

Davis, Nathaniel: Los dos últimos años de Salvador Allende, Ed. Plaza y Janés, Barcelona, 1987.

Drake, Paul W.: "The Chilean Socialist Party and coalition politics, 19321946", Hispanic American Historial Review, n. ${ }^{\circ}$ 53, Durham, NC, noviembre 1973.

Debray, Rogers: Conversaciones con Allende, Ed. Siglo XXI, México, 1971.

Derés, Eduardo, y Díaz, Carlos: "Pensamiento socialista en Chile», Antología 1893-1933, Documentas, Santiago de Chile, 1987. 
Doмıc, Juraj: La vía no capitalista de desarrollo, Ed. Vaitez, Santiago de Chile, s/f.

Dominguez, Eliodoro: La revolución en marcha, Santiago de Chile, 1942.

Dominguez, José: ¿Por qué fracasó el socialismo en Chile?, Ed. Zero, Madrid, 1974.

DOoner, Patricio: "La prensa de derecha durante el gobierno de la Unidad Popular", ICHEH (Documento de trabajo), Santiago de Chile, 1983.

Drake, Paul: Socialism and populism in Chile: 1932-1952, University of Illinois, Chicago, 1978.

Espinoza Orellana, Manuel: "El socialismo chileno frente a una encrucijada", en Arauco, n.․ 60, Santiago de Chile, enero 1965.

Faletto, Enzo: Algunas características de la base social del Partido Socialista y del Partido Comunista 1958-1973, FLACSO, Santiago de Chile, 1980.

FAUNDEZ, Julio: Marxism and democracy in Chile from 1932 to the fall of Allende, Yale University Press, London, 1988.

FEINBERG, Richard E.: "The triumph of Allende: Chile's Legal Revolution", New American Library, New York, 1972.

Fernández Figueroa, Juan: «El pueblo en la Patria política», en Índice, n.으 190-191, Madrid, mayo 1971.

FERNÁNDEZ JILBERTO, Alex: "Socialismo y socialdemocracia en América Latina: la social-democracia de la política en Chilen, en Revista Paraguaya de Sociología, Asunción, 1989.

Fermandols, Jorge: Chile y el mundo 1970-1973, Ed. Universidad Católica, Santiago de Chile, 1985.

Flores Olea, Víctor: Socialismo y política en América Latina: Argentina, Brasil, Chile, Perú y Uruguay, J. Álvarez, Buenos Aires, 1966.

FoxLEY, Alejandro, y otros: Chile, búsqueda de un nuevo socialismo, Ed. Nueva Universidad, Santiago de Chile, 1971.

Gamero, Marco Andrés: "Elementos para el análisis y la investigación del proceso político chileno 1970-1973", Revista Mexicana de Sociología, n.․ 36, México, julio-septiembre 1974 . 
Garay Vera, Cristian: "Vía chilena hacia el socialismo. ¿Incursiones en el leninismo?", en Revista de Derecho Político, n.o 41-42, Santiago de Chile, enero-febrero 1987.

Garay, Mario: La crisis politica y el Partido Socialista Popular, Prensa Latinoamericana, Santiago de Chile, 1968.

Garcés, Joan: Allende y la experiencia chilena, Ed. Ariel, Barcelona, 1972.

- Chile: el camino político hacia el socialismo, Ed. Ariel, Barcelona, 1972.

- Democrazia e contrarivoluzione in Chile, Cromotipia E. Sormani, Milano, 1977.

- El Estado y los problemas tácticos en el gobierno de Allende, Siglo XXI, México, 1974.

Garretón, M. Antonio: Politica y sociedad en un proyecto socialista, FLACSO, Santiago de Chile, s/f.

- "Reconstruyendo la izquierda", en Análisis, n. 62, Santiago de Chile, 17 de octubre de 1983.

Garretón, M. A., y Moulián, Tomás: La Unidad Popular y el conflicto político en Chile 1970-1973, Ed. Minja, Santiago de Chile, 1983.

Gı, Federico (compilador): Chile 1970-1973: lecciones de una experiencia, Ed. Tecnos, Madrid, 1977.

GonzÁlez, Fco. Javier: El Partido Socialista de Chile 1933-1958, UNAM, México, 1958.

Gonzáles Aguayo, Leopoldo: "La izquierda en el poder", Cuadernos Americanos, $\mathrm{n}$. ㅇ 175, México, marzo-abril 1971.

GonzÁlez RoJas, Eugenio: Socialismo frente al liberalismo, Ed. Quimantú, Santiago de Chile, 1972.

GroB, Jorge: El socialismo real y positivo, su constitución económica y política, Imp. General Días, Santiago de Chile, 1937.

GuZmán, E. de: «Allende, Unamuno y Balmaceda», en Índice, n.ํ 301-302, Madrid, mayo, 1972.

HaRing, C. H.: "The Chilean Revolution of 1931 ", en Hispanic-American Historial Review, mayo, 1933. 
Hidalgo, Paulo: "Pasado y presente de los partidos de izquierda: un ensayo interpretativo", CED, n. 109, Santiago de Chile, 1985.

HUASI, Julio: "Quién era el General Schneider y por qué murió", en Índice, n. 284-285, Madrid, febrero, 1971.

Huneeus, Carlos: "A propósito de los 40 años del Partido Socialista", en Política y Espíritu, n.ㅇ 343, Santiago de Chile, 1973.

lBÁNEEZ, Bernardo: El socialismo y el porvenir de los pueblos, Santiago de Chile, 1946.

Jobet, Julio César: El Partido Socialista de Chile, Ed. Prensa Latinoamericana, Santiago de Chile, 1971.

- "El Partido Socialista y el Frente Popular», en Arauco, n. 85, Santiago de Chile, febrero, 1961.

- El Socialismo a través de sus Congresos, Prensa Latinoamericana, Santiago de Chile, 1965.

- El Socialismo en Chile, Publicaciones del Congreso por la Libertad de la Cultura, Santiago de Chile, 1956.

- Historia del Partido Socialista de Chile, Ed. Documentos, Santiago de Chile, 1987.

- "La personalidad de Oscar Schnake y los primeros años del Partido Socialista", en Arauco, n. 73 , Santiago de Chile, 1966.

- Socialismo y Comunismo, Ed. Espartaco, Santiago de Chile, 1952.

- "Teoria y programa del Partido Socialista de Chile», en Arauco, n.ำ 27, Santiago de Chile, abril, 1962.

Jobet, Julio C., y Gaete, Gustavo: Homenaje del Partido Socialista Chileno a España Republicana, Santiago de Chile, 1938.

Jobet, Julio C., y Chelén, Alejandro: Pensamiento teórico y político del Partido Socialista Chileno, Ed. Quimantú, Santiago de Chile, 1972.

Kramer, Andrés: Chile: historia de una experiencia socialista, Ed. Península, Barcelona, 1973.

Kaufman, Edy: "La política exterior de la Unidad Popular Chilena", Foro Internacional, n. 66, México, octubre-diciembre 1976. 
LABARCA GoddARD, Eduardo: Chile al rojo. Reportaje a una revolución que nace, Ed. de la Universidad Técnica del Estado, Santiago de Chile, 1971.

LABROUSE, Alain: L'experience chiliene: réformisme ou révolution?, Ed. Seúl, París, 1972.

Lagos, Ricardo: Democracia para Chile. Propuestas de un socialista, Pehuén, Santiago de Chile, 1985.

- Democracia que anhelamos: Programa del Partido por la Democracia, PPD, Santiago de Chile 1989.

- Dos conceptos claves de la renovación socialista en Chile, Ed. Nueva Sociedad, Caracas, 1981.

— "Hacia la democracia», Documentos, Santiago de Chile, 1987.

Lavin, Mario: Chile frente al socialismo y al comunismo, Ed. Ercilla, Santiago de Chile, 1934.

LavretSkı, J.: Salvador Allende, Ed. Progreso, Moscú, 1978.

Maestre Alfonso, Juan: "Chile: revolución y contrarrevolución», en Cuadernos para el Diálogo, Madrid, 1973.

Malra Aguirre, Luis: Dos años de Unidad Popular, Ed. Quimantú, Santiago de Chile, 1973.

Mercier Vega, Luis: "Chile: una izquierda ambigua", en Mundo Nuevo, n. 56, París, febrero 1971.

Millas, Hernán, y FilıPP, Emilio: Chile 1970-1973. Crónica de una experiencia, Ed. Zig-Zag, Santiago de Chile, 1974.

Mistral, Carlos: "Chile: del triunfo popular al golpe fascista", Ed. Era, México, 1974.

Moss, Robert: El experimento marxista en Chile, Ed. Gabriela Mistral, Santiago de Chile, 1974.

Moulı́́N, Tomás: «Cuestiones de teoría política marxista: una crítica a Lenin", FLACSO (Documento de trabajo), Santiago de Chile, 1980.

- "Dictaduras hegemonizantes y alternativas populares", FLACSO (Documento de trabajo), Santiago de Chile, 1981.

- "Evolución histórica de la izquierda chilena: influencia del marxismo", FLACSO (Documento de trabajo), Santiago de Chile, 1982. 
- "La Crisis de la Izquierda", Revista Mexicana de Sociología, n. 44, México, abril-junio 1982.

- Línea estratégica de la izquierda: frentismo, populismo, antirreformismo, FLACSO, Santiago de Chile, 1982.

Moulián, Tomás, y otros: América Latina 80: Democracia y Movimiento Popular, DESCO, Lima, 1981.

Mujal-LeÓn, Eusebio M.: "The communist party of Chile, 1969-1973: the limits of pluralism», World Affairs, n. 136, Washington, 1973.

Muñoz, Heraldo; Núñez, Juan; KIRKwood, Julieta; Baño, Rodrigo; Calderón, Alfonso; Núñez, Enzo; Trabullo, Eduardo; Pinto, Aníbal, y Lagos, Ricardo: Temas socialistas, Ed. Vector, Santiago de Chile, 1983.

O’Brien, Philip: «Allende's Chile», Praeger, New York 1976.

OpPenHeIm, Luis Héctor: "The chilean road to socialism", en Latin-America Research Review, n.․ 1, Universidad de Nuevo México, Alburquerque, 1989.

Orrego Altamirano, Carlos: Ocho tesis sobre una estrategia socialista para Chile, Mimeo, Santiago de Chile, 1980.

Orrego V., Claudio: «Las contradicciones ideológicas, intereses de la Unidad Popularn, en Política y Espíritu, n. 330, Santiago de Chile, 1972.

OrTIZ, Eduardo: "El proyecto socialista y el tema de la democracia», en Opciones, n.ำ 10, Santiago de Chile, 1987.

Ovalle, Pedro: Libro negro de Chile, SPEIRO, Madrid, 1975.

Palma, Gabriel: La vía chilena al socialismo, Siglo XXI, México, 1973.

Partido por la Democracia: ¿Qué es el PPD?, documentos oficiales, Atanor, Santiago de Chile, 1989.

Partido Socialista: Declaración de principios, estatutos y reglamento orgánico del Partido Socialista de Chile, Santiago de Chile, 1957.

- La línea política del Partido Socialista, Dpto. de Publicaciones, Santiago de Chile, 1941.

- Primer Congreso de los Partidos Democráticos y Populares de América Latina, Imp. Gutenberg, Santiago de Chile, 1940. 
Partido Socialista Auténtico: Pacto de acción política: Partido Socialista Auténtico, Partido Comunista, Santiago de Chile, 1946.

Partido Socialista Unificado: Declaración de principios y reglamentos, tesis política mundial e himno del partido, La Nación, Santiago de Chile, 1947.

Perceval: iY ganó Allendel, Nueva Aurora, Santiago de Chile, 1964.

Pollack, Benny: "The chilean socialist party: Prolegomena to its ideology and organization", Journal of Latin American Studies, n. 10, Cambridge, mayo 1978.

Pollac, Benny, y RosenKUANz, Herman: Revolutionary Social Democracy/ The Chilean Socialist Party, Frances Pinter (Publishers), London, 1986.

Puccio, O.: Un cuarto de siglo con Allende: recuerdos de su secretario privado, Ed. Emisión, Santiago de Chile, 1987.

Puelma, Mario: "Chile 1970-1973. Die zerschlagung seiner Demokratie", Schweizensches ost-Instituit, Berna, 1975.

Queralt, Juan: "Con Fidel de Norte a Sur", en Índice, n.. 301-302, Madrid, mayo 1972.

Ramma Facal, Carlos M.: Chile: mil días entre la revolución y el fascismo, Ed. Planeta, 1974.

Ribero, Darcy: «Salvador Allende y la izquierda desvariada», en Portada, n. 1 , Lima, 1973.

Rodriguez, Aniceto: Forjando la Unidad Popular, Prensa Latinoamericana, Santiago de Chile, 1956.

- La lucha por el socialismo, Nuevos Rumbos, Caracas, 1980.

- "La victoria popular chilena", Informe al XXIII Congreso del Partido Socialista de Chile, La Serena, enero 1971.

Rodriguez, Felipe: Crítica a la Unidad Popular: 1970-1973, Fontamara, Barcelona, 1975.

Rodríguez Grez, Pablo: Entre la tiranía y la democracia, Edición del autor, Santiago de Chile, 1972.

Rojas SANFORD, Robinson: "The Murder of Allende and end of the chilean to socialism", Harper \& Row, New York, 1976. 
Rouceck, Joseph S.: "La presidencia de Allende", Revista de Estudios Políticos, n.ำ175, Madrid, enero-febrero 1971.

RUiz Esouide, Mariano: El socialismo traicionado, Ed. del Pacífico, Santiago de Chile, 1973.

Sebastián, Jean: La opción socialista, Terranova Ed., Santiago de Chile, 1986.

SILVA, Lautaro: Allende, fin de una aventura, Ed. Patria Nueva, Santiago de Chile, 1974.

SILVert, Kalman H.: El socialismo en Chile, Publicaciones del Congreso por la Libertad y la Cultura, Santiago de Chile, 1956.

Smirnov, Gabriel: La revolución desarmada, Chile 1970-1973, Ed. Era, México, s/f.

Sobel, Lester A.: Chile and Allende, Facts on File, New York 1974.

StePhAN de Uylder: Allende's Chile: The Political Economy of the rire and fall of the Unidad Popular, Cambridge University Press, Cambridge, 1976.

TeItelboin, Volodia: Otra vez sobre los acontecimientos de Chile, Ed. Internacional Paz y Socialismo, Praga, 1978.

TEXIER, Jorge: "Chile: First year of popular goverment», World Marxist Review, n. 14 , Toronto/Ontario, octubre 1971.

Tierno Galván, Enrique, y otros: Liberalismo y socialismo: problemas de la transición. El caso chileno, Tucar Ediciones, Madrid, 1975.

TıMosı, Jorge: «Un año de Unidad Popular: entrevista con Salvador Allende", en Índice, n.ำ296-297, Madrid, octubre 1971

TOER, Mario: "La vía chilena: un balance necesario", Ed. Tiempo Contemporáneo, Buenos Aires 1974.

Тона: Allende, democracia intransigente, Eds. América, Santiago de Chile, 1986.

Tourain, Alain: Vie et mort du Chili Populaire Juillet-Septembre 1973, Ed. Seuil, París, 1973.

TURrent, Isabel: La llama soviética en América Latina. El ocaso de la Unidad Popular chilena 1970-1973, Colegio de México, México, 1984. 
- La Unión Soviética en América Latina. El ocaso de la Unidad Popular 'chilena 1970-1973, Colegio de México, México, 1984.

VALDÉs, Jaime: La clave dorada de la UP, Ed. del autor, Santiago de Chile, $\mathbf{s} / \mathbf{f}$.

Valle Hernández, Jorge, y Díaz Gallardo, José: «Federación de la Juventud Socialista. Apuntes históricos, 19351973", Documentas, Santiago de Chile, 1987.

VARAS, Augusto: "La dinámica política de la oposición durante el gobierno de la Unidad Popular", FLACSO (Documento de trabajo), Santiago de Chile, 1976.

VARIOS Autores: "El gobierno de Allende y la lucha por el socialismo en Chilen, Cuadernos del Seminario de teoría del desarrollo, Instituto de Investigaciones Económicas, México, 1976.

- "Qué pasa en Chile. Los 50 días que cambiaron una Nación" (Monográfico sobre la victoria de Allende en 1970), Índice, $\mathrm{n} .{ }^{\circ}$ 280-281, Madrid, diciembre 1970.

VIAL, Alejandro: «El consenso, la izquierda y los comunistas en el sistema de partidos políticos", FLACSO (Documento de trabajo), Santiago de Chile, 1989.

Vodanovic Schnake, Hernán: Un socialismo renovado para Chile, Ed. Andante, Santiago de Chile, 1988.

WaIss, Oscar: Chile vivo, memorias de un socialista 1928-1970, Centro de Estudios Salvador Allende, Madrid, 1985.

- Nacionalismo y socialismo en América Latina, Ed. Iguazú, Buenos Aires, 1954.

- Pensamiento y política del Partido Socialista, Ed. Quimantú, Santiago de Chile, 1972.

- Presencia del socialismo en Chile, Ed. Espartaco, Santiago de Chile, 1952.

WALKER, Ignacio: "Del populismo al leninismo y la inevitabilidad del conflicto. El Partido Socialista en Chile (1933-1973)", CIEPLAN, Santiago de Chile, diciembre 1986.

WITTEM, Alejandro: «Allende: socialismo y democracia», en Crítica, n. 30 y 31, Universidad Autónoma de Puebla, Puebla, 1987. 
- Chile hacia el socialismo, Universidad de Chile, Santiago de Chile, 1970.

- El socialismo latinoamericano. Antología bibliográfica, Universidad de Puebla-Centro de Estudios Latinoamericanos Salvador Allende, Puebla, 1986.

- Estudio y Partido, Partido Socialista de Chile, Concepción, 1971.

- La acción escrita de los socialistas chilenos, Centro de Estudios Latinoamericanos, Salvador Allende, Puebla, 1987.

- Salvador Allende 1908-1973. Proceso de la liberación nacional, UNAM, México, 1980.

WoLPIN, Miles D.: "La Izquierda chilena: Factores estructurales que dificultan su victoria electoral en 1970", Foro Internacional, n. ${ }^{\circ}$ 33, México, julio-septiembre 1968.

Yocelvzky, Ricardo A.: "El Partido Socialista de Chile bajo la dictadura militar», en Foro Internacional, n. 105, México D.F., julio-septiembre, 1986.

Zammit, Joanne: The Chilean Road to Socialism, University of Texas Press, Austin, 1973.

ZañARTU, Mario, y OrRego, Claudio: Socialismo, propietarismo y liberaciones del pueblo, IDEP, Santiago de Chile, 1971.

Zemelman, Hugo: Estado, poder y lucha política, Casa de Chile, México, 1986.

- El proceso de transformación y los problemas de dirección política 1970-73, El Colegio de México, 1974.

\subsection{Partido Comunista}

Arriagada, Genaro, y Orrego, Claudio: Leninismo y Democracia, Ed. Aconcagua, Santiago de Chile, 1976.

ArriagadA, Genaro; OrRego, Claudio, y otros: Subversión y contrasubversión, CISEC, Santiago de Chile, 1978.

Baraibar, Carlos D.: Las nuevas tácticas del comunismo en Chile, Estudios sobre el comunismo, Santiago de Chile, 1956. 
Bascuñán Edwards, Carlos: "Los partidos de izquierda en Chile (19731983): el Partido Comunistan, ICHEH (Documento de trabajo), Santiago de Chile, 1981.

Benavente Urbina, Andrés: "Partido Comunista Chileno: su estrategia política entre 1973-1984», en Política, n. 8, Santiago de Chile, 1985.

- "Partido Comunista y sindicalismo politizado", CEP (Documento dde trabajol, Santiago de Chile, marzo 1984.

Boye, Otto: El Partido Comunista y su actual camino, Estudios Humanísticos, Santiago de Chile, 1987.

Cerda, Carlos: El leninismo y la victoria popular, Ed. Quimantú, Santiago de Chile, 1971.

Contreras Labarca, Carlos: Adelante en la lucha por el programa del Frente Popular, Eds. del Comité Central del Partido Comunista de Chile, Santiago de Chile, 1940.

- Hacia dónde va Chile. Por el pan, la tierra, la paz y la libertad de Chile, Eds. América, Montevideo, 1940.

- La lucha del pueblo por la reorganización de Chile: Informe ante el Congreso Nacional del Partido Comunista, Eds. Nueva América, Santiago de Chile, 1946.

- «Por la paz, por nuevas victorias del Frente Popular. Informe ante el XI Congreso Nacional del Partido Comunista", Santiago de Chile, 1939.

- Unión Nacional y el Partido único, Santiago de Chile, 1944.

CoRVAlán LePe, Luis: A combatir a todo sol y aire, al frente de las masas, por la conquista de un gobierno popular, Imp. Horizonte, Santiago de Chile, s/f.

- Algo de mi vida, Ed. Posada, México, 1977.

- Camino de la victoria, Ed. Horizonte, Santiago de Chile, 1972.

- "Comunists Tachts relative to agresion reform in Chile", en Smicht, Lynn (ed.): Agrarian Reform in Latin America, New York, 1965.

- Chile 1970-1973, Sofía Press, Sofía, 1978.

- Chile y el nuevo Panorama mundial, Santiago de Chile 1959. 
- El poder popular, única alternativa patriótica y revolucionaria (Informe al XIV Congreso del Partido Comunista), Imp. Horizonte, Santiago de Chile, 1969.

- Ésta y no otra es la política de los comunistas, Imp. Horizonte, Santiago de Chile, 1964.

- La rebelión popular se abre camino en Chile, s/e, s/l, 1981.

- La revolución chilena: sus grandes méritos y las causas de su derrota, Ed. Colo-Colo, Santiago de Chile, 1978.

- "Seguir avanzando con las masas", Documentos del XIII Congreso Nacional del Partido Comunista Chileno, Santiago de Chile, 1965.

- "The Struggle for a People's Government in Chiles", en World Marxist Review, vol. V, diciembre 1962.

- Todo Chile contra la política reaccionaria de Alessandri, Santiago de Chile, 1960.

- Todo lo deciden las masas, Imp. Horizonte, Santiago de Chile, 1965.

- Tres períodos de nuestra línea revolucionaria, Verlag Zest Bild, Desdem, 1982.

CORVALÁn Vera, Manuel: La organización de la acción política, Imp. Ecos, Santiago de Chile, 1964.

Cruzat, Ximena, y Deves, Eduardo: Recabarren. Escritos de prensa, Ed. Terranova, Santiago de Chile, 1985.

ChelÉn Rojas, Alejandro: Tres hombres: Marx, Recabarren, Grove, Chañaval, 1939.

DeVES VALDÉs, Eduardo: La praxis y la temporalidad latinoamericana a la hora de la obra de Luis Emilio Recabarren, Univ. Casa de Lovaina, 1978.

Díaz, Víctor: Por un Partido Comunista de masas, s/e, Santiago de Chile, 1965.

Domic K., Juraj: "El Partido Comunista liquida la vía al socialismo», en Portada, n. 38, Santiago de Chile, 1973.

- "Política militar del Partido Comunista de Chile», Ed. del autor, Santiago de Chile, 1988. 
- Fundamentos de la praxis marxista-leninista en Chile, Ed. Vartea, Santiago de Chile, 1976.

FERnÁndez LaRRAín, Sergio: Informe sobre el comunismo rendido en la Convención General del Partido Conservador Unido..., Ed. Zig-Zag, Santiago de Chile, 1954.

FouRnAL, George: "Le chili dans le mouvement révolutionaire de I'Amérique Latine", Cahiers du Communisme, n.ำ 1, París, noviembre 1971.

Fuentes, Hugo: Juventudes Comunistas. El dilema de la Juventud Demócrata Cristiana, Imp. Horizonte, Santiago de Chile, 1964.

Fuentes W., Manuel: Terrorismo comunista en Chile, ECOS, Santiago de Chile, 1981.

FuRCl, Carmelo: The political strateggy of the Chilean Communist Party 1950-1980, Institute of Latin America Studies, London, 1981.

Godoy UrRutia, César: Vida de un agitador, Universidad Autónoma de Sinaloa, Culiacán, 1982.

Gómez, M.e Soledad: Partido Comunista de Chile. Factores nacionales e internacionales de su política interna (1922-1952), FLACSO, Santiago de Chile, 1984.

González, Galo: Corvalán. Chili. Les Comunistes dans la marche au socialisme, Editions Sociales, parís, 1972.

- La lucha por la formación del Partido Comunista Chileno, s/e, Santiago de Chile, 1958.

GonzÁlez, José: Curso elemental sobre el Partido, Imp. Horizonte, Santiago de Chile, 1964.

InostrozA, Hugo Omar: El Partido. ¿Factor de cambio?, ICPA, Santiago de Chile, 1968.

INSULSA, José Miguel: "Eurocomunismo y Socialismo Europeo en la situación chilena", Foro Internacional, n.. 83, México, enero-marzo 1983.

INZUNZA, Jorge: "La question du pouvoir: tâche de masses", Cahiers du Comunisme, n.․ 10, París, 1971.

Jiles Pizarro, Jorge: Partido Comunista de Chile, Academia de Ciencias Políticas, Santiago de Chile, 1957. 
Jobet, J. C.; BarRíA, Jorge, y Vitale, Luis: Obras selectas de Luis Emilio Recabarren, Ed. Quimantú, Santiago de Chile, 1977.

LabARCA, Eduardo: Corvalán: 27 horas, Ed. Quimantú, Santiago de Chile, 1972.

- El Chile de Luis Corvalán, Ed. Fontamara, Barcelona, 1975.

- Vida y lucha de Luis Corvalán, Ed. Cultura Popular, México D.F., 1976.

LAFERTE, Elías: Vida de un comunista. Páginas autobiográficas, Ed. Austral, Santiago de Chile, 1971.

Marín Balmaceda, Raúl: $O$ arrasamos al comunismo o el comunismo arrasa a Chile, Santiago de Chile, 1948.

MezA, Francisco: "El Comunismo ante la ley chilena», Santiago de Chile 1947.

Millas Correa, Orlando: Derrotar a la derecha, Imp. Horizonte, Santiago de Chile, 1963.

- El humanismo científico de los comunistas, Ed. Andrés Bello, Santiago de Chile, 1968.

- Los comunistas los católicos y la libertad, Ed. Austral, Santiago de Chile, 1964.

Miranda Casanova, Hugo: Los delitos en la Ley de Defensa Permanente de la democracia, Ed. Universitaria, Santiago de Chile, 1959.

Neruda, Pablo: Confieso que he vivido. Memorias, Seix-Barral, Barcelona, 1974.

Partido Comunista de Chile: A la democracia con todo, Informe al Comité Central, y Resoluciones del XV Congreso del Partido Comunista, s/e, s/l, 1989.

- A través de la lucha de masas. Hacia la conquista de un gobierno popular en que la clase obrera tenga las principales responsabilidades, Imp. Horizonte, Santiago de Chile, s/f.

- El Estado policial o la Ley de Defensa de la Democracia, Santiago de Chile, 19SI.

- Estatutos del Partido Comunsita aprobados en el XII Congreso Nacional, Imp. Horizonte, Santiago de Chile, 1962. 
- Informe a los miembros del Comité Central. Síntesis de las consideraciones políticas, Mimeo, s/l, 1986.

- JJ.CC. La juventud frente a la clase obrera por la revolución, Imp. Horizonte, Santiago de Chile, 1966.

- "La tierra para quien la trabaja", Documentos del XII Congreso Nacional del Partido Comunista de Chile, Imp. Horizonte, Santiago de Chile, 1966.

- Nuestros caminos conducen al socialismo, Imp. Horizonte, Santiago de Chile, 1966.

- Programa del Partido Comunista, Imp. Horizonte, Santiago de Chile, 1962.

- Unidad y lucha del pueblo hasta vencer, Mimeo, s/l, 1988.

Partidos Comunistas del Cono Sur: "Declaración de los Partidos Comunistas del Cono Surn, Lima, noviembre 1982.

Pizarro, Jorge J.: Partido Comunista de Chile, Academia de Ciencias Políticas, Santiago de Chile, 1957.

Ramirez Necochea, Hernán: Orígenes y formación del Partido Comunista de Chile, Ed. Austral, Santiago de Chile, 1965.

Recabarren, Luis Emilio: Obras completas, Ed. Recabarren, Santiago de Chile, 1965.

Recabarren, Sergio: Mensaje vigente, A. S., Ltda., Santiago de Chile, 1964.

SANHUEZA, Gabriel: Santiago Arcos: comunista, millonario y calavera, Ed. del Pacífico, Santiago de Chile, 1956.

Silva Solar, Julio: A través del marxismo, Ed. del Pacífico, Santiago de Chile, 1951.

UNIÓN NACIONAL: "La violencia política en las propias palabras del Partido Comunista chileno", en Realidad, n.ำ 9, Santiago de Chile, 1986.

Varas, Augusto y otros: El Partido Comunista de Chile. Estudio multidisciplinario, CESOC, Santiago de Chile, 1988.

- "Partido Comunista en Chile», FLACSO, Santiago de Chile, 1988. 
Vitale, Luis: Obras escogidas de Luis Recabarren, Ed. Recabarren, Santiago de Chile, 1965.

Yopo, Boris, y otros: El Partido Comunista en Chile, CESOC-FLACSO, Santiago de Chile, 1988.

\subsection{Otras obras sobre diferentes movimientos de la izquierda}

API: Estatutos y principios, Mimeografiado, Santiago de Chile, 1972.

Ambrosio, Rodrigo: Sobre la construcción del Partido, Ed. Barcos de Papel, Santiago de Chile, 1972.

Benavente Urbina, Andrés: "Movimiento de Izquierda Revolucionaria: trayectoria y presente", en Política, n. 12 , Santiago de Chile, julio 1987.

- "Panorama de la izquierda chilena 1973-1984", CEP (Documento de trabajo), Santiago de Chile, 1985.

- "Perfil del Partido Humanista", en Política, n.. 14, Santiago de Chile, diciembre, 1987.

CoRTÉs TenZI, Antonio: Problemas estratégicos en la lucha del pueblo chileno, México, 1978.

Cuarta Internacional: Por el camino de la revolución: resoluciones del Primer Congreso Latinoamericano del Trotskismo, Ed. POR, Santiago de Chile, 1940.

EnRíouez, Miguel: «El camino del poder popular», en El Rebelde, Santiago de Chile, 1973.

KoudACHKIW, M. T.: Chile: la experiencia de la lucha por la unidad de las fuerzas de izquierda y la transformación revolucionaria. Ed. Progreso, Moscú, 1978.

MAIRA, Luis: "Chile: Autoritarismo, democracia y movimiento popular", CIDE, México 1984.

MOVIMIENTO de IzQUIERDA ReVolucionaria: A conquistar el poder revolucionario de obreros y campesinos, Santiago de Chile, 1971. 
- EI MIR junto a la revolución cubana, Prensa Latinoamericana, Santiago de Chile, 1971.

- EI MIR: su propuesta, Santiago de Chile, 1984.

- El pacto constitucional y el futuro democrático de Chile, Santiago de Chile, 1984.

- La política y la situación actual, Santiago de Chile, 1986.

- Lo Hermida: la cara fea del reformismo, Santiago de Chile, 1972.

- Posición del MIR: elecciones no, la lucha armada único camino, Prensa Latinoamericana, Santiago de Chile, 1969.

- Táctica para la lucha de resistencia, s/e, s/l, s/f.

MuÑoz, Heraldo: "Inserción internacional de partidos de izquierda chilenos. Un análisis en la perspectiva de redemocratización", en Opciones, n. $\stackrel{3}{3}$, Santiago de Chile, 1984.

Pascal Allende, Andrés: El manejo de la táctica política, Santiago de Chile, 1982.

- La crisis nacional y la política de los revolucionarios, Santiago de Chile, 1986.

- "Relaciones de poder en una localidad rural. Estudio del caso del VaIle Hurtado", Coquimbo, ICIRA, Santiago de Chile, 1968.

Rodríguez Elzondo, José: Mitología de la ultra-izquierda chilena, Ed. Austral, Santiago de Chile, 1971.

Roussant, Claude M.: Política de unidad de la izquierda chilena 1956-1970, Centro de Estudios Internacionales, Colegio de México, México D.F., 1973.

USOPO: Programa político, Imp. Prensa Latinoamericana, Santiago de Chile, 1968.

VARIOS AUtores: MIR, Ed. Zero, Madrid, 1976.

VIAL, Alejandro: Una hipótesis sobre la izquierda chilena, FLACSO, Santiago de Chile, 1989.

Vusckovic, Pedro: «El futuro próximo del pueblo chileno", Estudios Políticos (nueva época), n. 3, México, julio-septiembre 1987.

- Una sola lucha, IEPALA, Leganés (Madrid), 1978. 


\section{FUERZAS SOCIALES}

\subsection{Sindicalismo y movimiento obrero}

ADARo DIDIER, Ismael: El sindicalismo agrícola como solución al problema agrario, s/e, Santiago de Chile, 1921.

ALfonso, A., y otros: Movimiento campesino chileno, Ed. ILIRA, Santiago de Chile, 1970.

AngelL, Alan: "The origins of the chilean Labor Mouvement", en Peasants and proletarians: the struggles of third world workers, editado por Robin Cohen Peter, C. W. Gutkinds y Phillys Brazier, Monthly Review Press, New York, 1980.

Arias Escobedo, Osvaldo: La prensa obrera en Chile, Ed. Pla, Santiago de chile, 1970.

Barrera, Manuel: "Desarrollo económico y sindicalismo en Chile: 19381970 ", Revista Mexicana de Sociología, n. 42, México, julio-septiembre 1980.

- El sindicato industrial, Universidad de Chile, Facultad de Ciencias Económicas, Santiago de Chile, 1965.

- "Perspectiva histórica de la huelga obrera en Chile», Cuadernos de la Realidad Nacional, n. 9, Santiago de Chile, septiembre 1991.

BARRERA, Manuel, y otros: Sindicato y Estado en el Chile actual, UNIRSO, Suiza, 1985.

Barria Serón, Jorge: "Chile, la cuestión política y social en 1920-1926", en Anales de la Universidad de Chile, Santiago de Chile, octubre-diciembre, 1959.

- "El movimiento campesino chileno", en Temas Laborales, INSORA, Santiago de Chile, 1969.

- El movimiento obrero de Chile, Universidad Técnica del Estado, Santiago de Chile, 1972.

- La historia de la CUT, Ed. de Prensa Latinoamericana, Santiago de Chile, 1971. 
- Los movimientos sociales a principios del siglo XX 1900-1910: memoria histórica, Imp. Universidad, Santiago de Chile, 1954.

- "Los sindicatos de la gran minería del cobre", INSORA, Santiago de Chile 1970.

- Trayectoria y estructura del movimiento sindical chileno 1946-1962, Instituto de Organización y Administración, Santiago de Chile, 1963.

Bitar, Sergio, y Pizarro, C.: La caída de Allende y la huelga de El Teniente, FLACSO, Santiago de Chile, 1986.

Bowen Herrera, Alfredo: Movimiento corporativo y sindicalismo agrícola, Imp. La Fama, Santiago de Chile, s/f.

Bravo LIRA, Bernardino: «El movimiento asociativo en Chile (19241973)", Separata de la Revista Política, Santiago de Chile, septiembre 1982.

СТСн: ¿Por qué salimos a la calle el 21 de mayo de este año?, Imp. Austral, Santiago de Chile, 1940.

Campero, Guillermo: "Las nuevas condiciones en las relaciones de trabajo y la acción política en Chilen, Revista Mexicana de Sociología, n.o 41, México, abriljunio 1979.

CAmpero, Guillermo, y Cortázar, René: "Lógicas de acción sindical en Chile», CIEPLAN, n. 18, Santiago de Chile, 1985.

Campero, Guillermo, y Valenzuela, José: El movimiento sindical en el régimen militar chileno: 1973-1981, ILET, Santiago de Chile, 1984.

Campos Sevilla, Marcial: El desarrollo obrero chileno y las determinaciones orgánicas del proyecto político de la Unidad Popular, FLACSO, México, 1978.

CANTONI, Wilson: "Poder popular en el agro chileno", Cuadernos de la Realidad Nacional, Santiago de Chile, 1972.

Cifuentes, J. M.: La cuestión social, Imp. de Chile, Santiago de Chile, 1921.

Confederación Latinoamericana de Sindicatos Cristianos: "Chilean ChristianDemocrats Set Trade-Union Policy", en CLASC, Santiago de Chile, 1966.

Departamento de Trabajo de Estados Unidos: Labor in Chile, Government Printing Office, Washington, 1962. 
Escobar Zenteno, A.: Desarrollo del Movimiento Obrero, s/e, Santiago de Chile, 1940.

FalABella, Gonzalo: "Capacidad hegemónica del sindicalismo en Chile autoritario", FLACSO, Santiago de Chile 1983.

Galdames, Luis: Los movimientos obreros en Chile, IV Congreso Científico, Santiago de Chile, 1911.

GARCÉs, Mario, y MiLos, Pedro: FOCH, CTCH, CUT. Las centrales unitarias en la historia del sindicalismo chileno, Santiago de Chile 1988.

Gomer, Sergio: Movimiento campesino chileno, ICIRA, Santiago de Chile, 1970.

GurRIERI, Adolfo: "Consideraciones sobre los sindicatos chilenos", en Aportes, n. ${ }^{9}$ 9, París, julio 1968.

Hurtado, Alberto: Sindicalismo: historia, teoria y práctica, Ed. del Pacífico, Santiago de Chile, 1950.

ÍñIGUEZ, Pedro Felipe: Notas sobre el desarrollo del pensamiento social en Chile 1901-1906, Ed. Jurídica, Santiago de Chile, 1968.

ItURRASPE, Francisco (ed.): Participación, cogestión y autogestión, UNITAR, Santiago de Chile, 1986.

JILIBERTO, R.: “¿Libertad sindical o sindicalizar la libertad?», Vector-Documentos, Santiago de Chile, 1986.

Jobet, Julio César: Los precursores del pensamiento social en Chile, Ed. Universitaria, Santiago de Chile, 1955.

- Recabarren y los orígenes del movimiento obrero y el sindicalismo chileno, Prensa Latinoamericana, Santiago de Chile, 1973.

Lagos Valenzuela, Tulio: Bosquejo histórico del movimiento obrero en Chile, Imp. El Esfuerzo, Santiago de Chile 1941.

LANDSBERGER, Henry, y otros: El pensamiento del dirigente sindical chileno, INSORA, Santiago de Chile, 1963.

Miaureira Lagos, Jorge: Ideología sindical cristiana para América Latina, Ed. Jurídica, Santiago de Chile, 1968.

Moreno, Ernesto: Historia del movimiento sindical chileno, $\mathrm{ICHEH}$, Santiago de Chile, 1986. 
Morris, J. O., y otros: Afiliación y finanzas sindicales en Chile, Ed. Universitaria, Santiago de Chile, 1962.

NúÑEz, Óscar: Chile visto por los trabajadores, Ed. Latinoamericana, Santiago de Chile, 1964.

Ortiz Letelier, Fernando: El movimiento obrero en Chile. Antecedentes 1881-1919, Libros del Meridion, Ed. Michay, Madrid, 1985.

Ortuzar, Gregorio, y PUENTE, Isaac: Hacia un mundo nuevo. Teoría y práctica del anarco-sindicalismo, Imp. Gutenberg, Valparaíso, 1938.

Piñera, José: La revolución laboral en Chile, Ed. Zig-Zag, Santiago de Chile, 1990.

Pizarro, C.: La huelga obrera en Chile, Ed. Sur, Santiago de Chile, 1986.

Poblete Troncoso, Moisés: El movimiento de asociación profesional obrera en Chile, FCE, México D.F., 1945.

- "El movimiento sindical chileno", en Combate, vol. IV, n. 23 , San José de Costa Rica, julio-agosto 1962.

Ramírez Necochea, H.: Historia del movimiento obrero en Chile. Antecedentes, Tall. Gráf. Lautaro, Santiago de Chile, 1956.

SADER, Emir: Movilización de masas y sindicalización en el gobierno de la Unidad Popular, CESOC, Universidad de Chile, Santiago de Chile, 1973.

Salinas, Maximiliano: Clotario Blest, Ed. Arzobispado de Santiago de Chile - Vicaría de la solidaridad, Santiago de Chile, 1980.

Schwataman, Simón: "Ideología política y participación obrera", Anales de la Facultad Latinoamericana de Ciencias Sociales, Santiago de Chile, enero-febrero 1964.

VITALE, Luis: Los discursos de Clotario Blest y la revolución chilena, Ed. POR, Santiago de Chile, 1961.

- Historia del movimiento obrero, Ed. POR, Santiago de Chile, 1962.

Veneros Ruis-TAGLE, Diana: "Evolución de la legislación laboral en Chile hasta 1924", en Dimensión histórica de Chile, n. 2 , Santiago de Chile, 1985.

WITKER, Alejandro: "El movimiento obrero chileno", en Historia del movimiento obrero latinoamericano, Ed. Siglo XXI-UNAM, México D.F., 1984. 
ZAPATA, Francisco: Estructura y representación del sindicalismo en Chile, ILPES, Santiago de Chile, 1968.

- "Las relaciones entre la Junta Militar y los trabajadores chilenos: 1973-1978", Foro Internacional, n. 20, México, octubre-diciembre 1979.

- «Las relaciones entre el movimento obrero y el Gobierno de Salvador Allende", Foro Internacional, n.․ 78, México D. F., octubre-diciembre 1976.

\subsection{Las iglesias y la política}

Antúnez Aldunate, Jaime: "La Iglesia y el Estado en el régimen militar chileno", en Razón Española, n.o 24, Madrid, julio-agosto 1987.

Araneda Bravo, Fidel: "Arzobispo Errazúriz y la evolución política y social de Chile», Ed. Andrés Bello, Santiago de Chile, s/f.

Boero, Mario: Iglesia y política. ¿Hacia una teología de la liberación en Chile?, Centro de Estudios Salvador Allende, Madrid, 1986.

Camus, Carlos: "Obispo de Linares: la iglesia chilena y el gobierno militarn, en Revista Mensaje, n. 337, Santiago de Chile, 1985.

Comité Permanente del Episcopado: "No callaremos ni tomaremos descanso", en Mensaje, n.ำ 347, Santiago de Chile, 1986.

Correa, Enrique, y Viera-Gallo, José Antonio: Iglesia y dictadura, Eds. Chile y América, Santiago de Chile, 1986.

CRISTIANOS POR el Socialismo: ¿Consecuencia cristiana o alineación política?, IDEP, Santiago de Chile, 1972.

DOONER, Patricio, Y TAGLE, Matías: «Relaciones entre la iglesia y los gobiernos de Chile: 1958-1975), CPU (Documento de trabajo), Santiago de Chile, 1976.

Donoso L., Teresa: Historia de los Cristianos por el Socialismo en Chile, Ed. Vaitea, Santiago de Chile, 1975.

Fontaine Talavera, Arturo, y Beyer, Harald: "Retrato del movimiento evangélico a la luz de las encuestas de opinión pública», en Estudios Públicos, n.․ 44, Santiago de Chile, 1991. 
GallleA, Carmen: El Pentecostal. Testimonio y experiencia de Dios, Centro Bellarmino-CISOC, Santiago de Chile, 1990.

- Lugares de culto religioso en Santiago, CISOC-Centro Bellarmino, Santiago de Chile, 1988.

Garcia-Huidobro Correa, J.: Tentación del poder. Expresión política de las creencias religiosas, Ed. Andrés Bello, Santiago de Chile, 1986.

Ginés Ortega, Jesús: El pensamiento político cristiano en la historia, IDEPTall. Gráf. Corp. Ltda., Santiago de Chile, 1972.

- Pensamiento cristiano y acción política, IDEP, Santiago de Chile, 1971.

González Pizarro, Juan Antonio: «El catolicismo chileno y la guerra civil española: 1936-1939. Notas y materiales para su estudion, Anuario de Estudios Americanos, vol. XLVII, Sevilla, 1990.

- "En torno a la separación de la Iglesia y el Estado", Anuario e Historia de la Iglesia, Santiago de Chile, 1983.

González EsPejo, Fernando: Cuatro decenios de la historia eclesiástica de Chile. Crónicas de las relaciones entre Iglesia y Estado (1831-1871), Santiago de Chile, 1948.

GuICHARD, Jean: "La estrategia política actual de la iglesia", en Índice, n.. 338-339, Madrid, octubre 1973.

GutiérRez Fuentes, J. Ignacio: La vicaría de la solidaridad, Alianza Editorial, Madrid, 1986.

HeviA, Renato: "Crónica de la Iglesia en Nicaragua y Chile, ¿persecución?", Revista Mensaje, n. 352, Santiago de Chile, 1986.

HoJman, Eugenio: "Mil novecientos sesenta $y$ tres - mil novecientos ochenta y nueve (1963-1989): memorial de la dictadura, Ed. Emisión, Santiago de Chile, 1990.

Hoover, W. C.: Historia del avivamiento pentecostal en Chile, Imp. Excelsior, Valparaíso, 1948.

HUerTA, M. Antonia, y PACHECO, Luis: La iglesia chilena y los cambios sociopolíticos, Ed. Pehvén-Centro Bellarmino, Santiago de Chile, 1988.

Katz, Claude: "Chile bajo Pinochet", Anagrama, Barcelona. 
KREBS, Ricardo, y otros: Catolicismo y laicismo. Las bases doctrinales del conflicto entre la Iglesia y el Estado en Chile 1975-1985, Ed. Nueva Universidad, Santiago de Chile, 1981.

Lagos, Humberto, y CHACÓN, Arturo: Los evangélicos en Chile: una lectura sociológica, Ed. Literatura Americana Reunida, Programa Evangélico de Estudios Socio-Religiosos, Santiago de Chile, 1987.

Lalive D'Epinay, Christian: El refugio de las masas. Estudio sociológico del protestantismo en Chile, Ed. del Pacífico, Santiago de Chile, 1968.

MARTIN, David: "Otro tipo de revolución cultural. El protestantismo radical en Latinoamérica", en Estudios Públicos, n. 44, Santiago de Chile, 1991.

Meneses C., Aldo: «Poder del discurso: la Iglesia Católica chilena y el Gobierno Militar: 1973-1984", ILADES, Santiago de Chile, 1989.

MoRANDÉ C., Pedro: "Aportes para la renovación ideológica humanista cristiana", Estudios Humanisticos, Santiago de Chile 1988.

OBISPOS DE CHLE: Evangelio, política y socialismo, Secretariado del $\mathrm{CECH}$, Santiago de Chile, 1971.

Ossorio Góngora, Mario y Jorge: La iglesia y la cuestión social en Chile (1920-1934), s/e, s/l, s/f.

Oviedo Cavada, Carlos: Moral, juventud y sociedad permisiva, Santiago de Chile, septiembre 1991.

PIKE, F.: The conflict between Church and Stade in Latin America, Knopf, New York, 1964.

Poblete, P., y Gallea, G.: Movimiento Pentecostal e Iglesia Católica en medios populares, Centro Bellarmino, Santiago de Chile, 1984.

Poblete, P.; Galilea, C., y von Drop, P.: Imagen de la Iglesia y religiosidad de los chilenos, Centro Bellarmino, Santiago de Chile, 1980.

Rayo, Gustavo, y Porath, William: Perfil y opciones políticas de los católicos chilenos, CERC, Santiago de Chile, 1990.

Sampedro N., Francisco, y otros: Pentecostalismo, sectas y pastoral, Comisión Nacional de Ecumenismo, Área Eclesial-Conferencia Episcopal de Chile, Santiago de Chile, 1989.

Segundo, Juan Luis: La iglesia chilena ante el socialismo, Fundación Manuel Larraín, Talca, 1971. 
Silva Cotapos, Carlos: Historia eclesiástica de Chile, s/e, Santiago de Chile, 1925.

Silva Henriquez, Raúl: La misión social del cristianismo. Conflicto de clases o solidaridad cristiana, Ed. Paulinas, Santiago de Chile, 1973.

Silva Henriouez, Raúl, y Precht Bascuñán, Cristian: El alma de Chile, CiePLAN, Santiago de Chile, 1986.

SMITH, Brian: The Church and Politics in Chile, Princeton University Press, Princeton, 1982.

TENNEKES, Hans: El movimiento pentecostal en la sociedad chilena, SubFacultad de Antropología Cultural de la Universidad Libre de Amsterdam e lquique, CIREN, Amsterdam, 1985.

Varios Autores: Teología política, Eds. Chile-América, Santiago de Chile, 1985.

Vergara, Ignacio: El protestantismo en Chile, Ed. del Pacífico, Santiago de Chile, 1962.

VICARÍA de LA SolidARIDAD: "Vicaría de la Solidaridad. Duodécimo año de labor", Vicaría de la Solidaridad, Santiago de Chile, 1987.

\subsection{Fuerzas Armadas y Gobierno Militar}

Ahumada, Arturo: El ejército y el 5 de septiembre, Reminiscencias, Santiago de Chile, 1931.

Almeyda, Clodomiro: Tres ensayos sobre las Fuerzas Armadas chilenas, Ed. Arauco, s/l, s/f.

AlReAR, Juan Carlos: "Pinochetismo y política», Ed. del autor, Santiago de Chile, 1988.

Ampuero, Raúl: La contrarrevolución militar en América Latina, Casa de Chile, México, 1977.

ANGELL, Alan: "Chile after five years of military rule", Current History, n. ${ }^{\circ}$ 76, Philadelphia, febrero 1979.

- "The chilean road to militarism", en International Journal, n. 29 , verano 1974. 
Arriagada Herrera, Genaro: El pensamiento político de los militares, Ed. Aconcagua, Santiago de Chile, 1987.

- La política militar de Pinochet, Ed. Privada, Santiago de Chile, 1985.

Arriagada Herrera, Genaro, y otros: Las FF.AA. en la sociedad civil, SISEC, Santiago de Chile, 1978.

- Seguridad nacional y bien común, CESOC, Santiago de Chile, 1976.

Arrovo, Gonzalo: Golpe de Estado en Chile, Ed. Sígueme, Salamanca, 1974.

Asbresa S., Renato: Jurisdicción penal-militar, Ed. Jurídica de Chile, Santiago de Chile, 1973.

Barzona URzUa, Pablo, y otros: "Fuerzas armadas y seguridad nacional", Ed. Portada, Santiago de Chile, 1973.

BenNeTt, Juan A.: La revolución del 5 de septiembre de 1924, Balcells \& Cía., Santiago de Chile, s/f.

Bertelsen Reppetto, Raúl: "Chile. La caída de un régimen", Nuestro Tiempo, n.․233, Pamplona, 1973.

Boye, Otto, y Nohlen, D.: “¿Era inevitable la contrarrevolución en Chile? Capas medias y militares en Chile», Revista Análisis, Santiago de Chile, 18 de octubre de 1983.

Bulnes, José María: "Chile en la hora de las dudas", Estudios Políticos, n. 9 5, México, enero-marzo 1976.

- "El caso de Chile", Estudios Políticos (nueva época), n. 3, México, julio-septiembre 1984.

Cárdenas, Juan Pablo: No a Pinochet, Ed. Emisión, Santiago de Chile, 1986.

Carvajal, Patricio, y Huerta, Ismael: "El Pronunciamiento militar de 1973: fundamentos y antecedentes", Política, n. ${ }^{4}$, Santiago de Chile, diciembre 1983.

Cavalla R., Antonio: Estados Unidos-América Latina: Fuerzas Armadas y defensa nacional, Cualicam (México), s/f.

Cavallo, Ascanio; Salazar, Manuel, y Sepúlveda, Óscar: La historia oculta del régimen militar: Chile 1973-1980, Ed. Antártica, Santiago de Chile, 1990. 
CED: FF.AA., Estado y Sociedad, CED-Hachette, Santiago de Chile, 1989.

Cirianno, Antonio: «Entrevista con el capitán general D. Augusto Pinochet Ugarte", Defensa, n.․171, Madrid, julio 1992.

Colegio de Abogados de Chlle: Justicia militar en Chile, Ed. Jurídica EDIARCONOSUR, Santiago de Chile, 1990.

Coliers, David: The New Autoritarism in Latin America, Princeton University Press, Princeton, 1979.

- «Comisión Nacional de Verdad y Reconciliación», Informe, La Nación, Santiago de Chile, 1991.

Córdova-Claure, Florencia: Operación Chile, Ed. Pomaire, Barcelona, s/f.

Córdova-Claure, Ted: ¿Chile sí?, Ed. de la Flor, Buenos Aires, Argentina, 1973.

- Chile no, Grupo Editor Buenos Aires, Buenos Aires, Argentina, 1974.

Corte Suprema: «Respuesta de la Corte Suprema al informe de la Comisión Nacional de Verdad y Reconciliación", Estudios Políticos, n. ${ }^{2} 42$, Santiago de Chile, 1991.

Correa, Raquel, y otros: "Los generales del Régimen", Ed. Aconcagua, Santiago de Chile, 1983.

Cuevas Farren, Gustavo: "Los actores políticos de oposición al Gobierno Militar y su oposición a las Fuerzas Armadas", en Política, n. 24-25, Santiago de Chile, diciembre 1990.

ChATEAU, Jorge: "Seguridad nacional y guerra antisubversiva", FLACSO (Documento de trabajo), Santiago de Chile, 1983.

- "Antecedentes teóricos para el estudio de la geopolítica y doctrinas castrenses. Notas para una investigación", "FLACSO (Documento de trabajo), Santiago de Chile, 1977.

Clerva, Ricardo de la: «El Chile que he visto», Razón Española, n.⒉ 29, Madrid, mayo-junio 1988.

Dossıer: "Los militares chilenos", Chile-América, n. 58-59, Roma, 1979.

DuRán S., Roberto: Las FF.AA. y la sociedad civil en Chile: Puntos de encuentro y divergencia en una sociedad redemocratizada, CED, Santiago de Chile, 1988. 
EJÉrCito de Chile: Síntesis de la presentación del Ejército a la Comisión Nacional de la Verdad y Reconciliación, Santiago de Chile, 1991.

Fernández Jilberto, Alex: Dictadura militar y oposición política en Chile, 1973-1981, CEDLA-Latin America Studies, Holanda, 1985.

FLISFISCH, Ángel: "Incentivos y obstáculos a la cooperación política en el Chile autoritario", en Materiales para la Discusión del CED, n. 187, Santiago de Chile, 1987.

FonTAINE, Arturo, y otros: Nuestro camino, Eds. Encina Litda., Santiago de Chile, 1976.

Frühling E., Hugo; Portales, Carlos, y Varas, Augusto: Estado y FF.AA., FLACSO, Santiago de Chile, 1982.

Fuerzas Armadas de Chile: Álbum histórico, Santiago de Chile, 1928.

Garay V., Cristian: "Doctrina Schneider-Prats: la crisis del sistema político y participación militar (1968-1973)", Política, n. 10, Santiago de Chile, diciembre 1986.

Garcia, P.: Las Fuerzas Armadas en Chile, Siglo XXI, México, 1974.

Garcia, Rigoberto, y otros: Chile 1973-1984, Lais, Estocolmo, 1987.

GarRetón, Manuel Antonio: «De la Seguridad Nacional a la nueva institucionalidad", Foro Internacional, n. ${ }^{\circ}$, México, julio-septiembre 1978.

- La cultura autoritaria de Chile, FLACSO, Santiago de Chile, 1981.

- "The Political Evolution of the Chilean Military Regimen and Problems in the Transition to Democracy", en O'Donnell, G.; Schmitter, P., y Whitehead: Transition from Authoritarian Rule-Latin America, John Hopkins University Press, Baltimore and London, 1986.

González Selanio, Víctor: "El largo viaje de un ejército hacia la noche. La experiencia chilena", en Nueva Sociedad, febrero 1986.

Gurriarán, José A.: Chile: el ocaso del General, El País-Aguilar, Madrid, 1989.

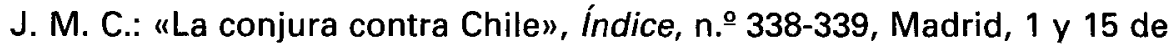
octubre 1973.

Joxe, Alain: Las Fuerzas Armadas en el sistema político chileno, Ed. Universitaria, Santiago de Chile, 1970. 
Junta Miltar de Gobierno: Declaración de principios del Gobierno de Chile, Imp. Filadelfia, Santiago de Chile, 1974.

- Chile marcha hacia el futuro, Imp. Filadelfia, Santiago de Chile, 1976.

- El Libro Blanco. Cambio de Gobierno en Chile, Ed. Lord Cochrane, Santiago de Chile, 1973.

Katz, Claude: Chile bajo Pinochet, Ed. Anagrama, Barcelona, 1975.

LAGos, Humberto: "La función de la religión en el gobierno militar, en el modelo militar autoritario y en las Fuerzas Armadas y de orden en Chile», Cuadernos ESIN, n. 4, Santiago de Chile, 1985.

- Crisis de la esperanza. Religión y autoritarismo en Chile, Eds. LAR, Santiago de Chile, 1988.

LóPez Gómez, Luis Ignacio: Chile, el largo camino al Golpe, Ed. Diro, Barcelona, 1974.

Maestre Alfonso, Juan: "La doctrina de la seguridad nacional en las Constituciones del Cono Sur de América Latina", en Caminos de la Democracia en América Latina, Fundación Pablo Iglesias, Madrid, 1984.

- Libro rojo del presidente Pinochet y la CIA, Akal, Madrid, s/f.

Maldonado Prieto, Carlos: Sobre doctrina y función de las FF.AA. chilenas: el caso del Servicio Militar obligatorio, ESIN-Instituto para el Nuevo Chile, Santiago de Chile, 1984.

- "Pasado y presente del poder militar en Chile", Affairs Internationals, n. 14 y 15, Berna, 1988.

- "Portales y la legitimación histórica del régimen militar chileno", Arauco, n. 1, Santiago de Chile, 1984.

Maldonado Prieto, Carlos, y Quiroga, Patricio: "La influencia prusiana a l'exércit xilé", Cuadernos de América, n. 3, Berna, 1987.

Mallor, James: Authoritarianism and Corporatism in Latin America, University of Pittsburgh Press, Pittsburgh, 1977.

MaURo M., Ruy: El reformismo y la contrarrevolución. Estudios sobre Chile, ERA, México, 1976.

MLLARC, René: "Significado y antecedentes del movimiento militar de 1924", Historia, n. 11, Santiago de Chile. 
Mistral, Carlos: "Chile: The Military Junta and its perspectives", Monthly Review, n. 25, New York, marzo 1974.

Mouna Johnson, Carlos: Chile: los militares y la política, Ed. Andrés Bello, Santiago de Chile, 1989.

Montealegre, Hernán: La seguridad del Estado y los derechos humanos, Ed. de la Academia de Humanismo Cristiano, Santiago de Chile, 1979.

MoREno Rivas, Antonio: "Sobre la democracia y los militares: El caso chileno", Revista Mexicana de Sociología, n. 37, México, julio-septiembre 1975.

Moulá́N, Tomás, y otros: Chile 1973-198...? FLACSO, Santiago de Chile, 1983.

MuÑoz, Heraldo: "La política exterior chilena: la crisis continúa", Foro Internacional, n.ำ 102, México, octubre-diciembre 1985.

- Las relaciones exteriores del gobierno militar chileno, Eds. del Ornitorrinco, Santiago de Chile, 1985.

Nogueira, Humberto, y Cumplido, Francisco: Las Fuerzas Armadas, ICHEH, Santiago de Chile, 1986.

NorTH, Luisa: "Los militares en la política chilena", Chile-América, n.ำ1011, Roma, 1975.

NunN, Frederick: "Chilean Politics 1920-1931: The honourable mission of the Armes Forces", University of New Mexico, Alburquerque, 1970.

- The Military in Chilean History: Essays on Civil-Military Relations 1810-1973, New Mexico University Press, Alburquerque, 1975.

- Emil Körner and the Prussianization of the Chilean Army in the Politics of Antipolitics, editado por Brian Loreman y Thomas M. Davis Jr., University of Nebraska Press, Lincoln \& London, 1978.

- «El profesionalismo militar chileno en el siglo XX", Cuaderno n. 3 del Instituto de Ciencia Política, Santiago de Chile, 1976.

- "Military-Civilian relations in Chile: The legacy of the golpe of 1973", Inter-American Economic Affaires, n. 9 29, Washington D.C., otoño 1975.

O'DonnelL, Guillermo: Modernization and Bureaucratic-Authoritarism. Studies in Southern Politics, University of California, Berkeley, 1973. 
O.E.A.: Informe sobre la situación de los derechos humanos en Chile, Washington D.C., 1985.

Opaso, Cristian (compilador): Informes del Senado de los EE.UU. Frei, Allende y la mano de la CIA, Eds. del Ornitorrinco, Santiago de Chile, $\mathrm{s} / \mathrm{f}$.

Ortuzar, Ximena: México y Pinochet: la ruptura, Ed. Nueva Imagen, México, 1986.

PALMA, Patricio: "Las Fuerzas Armadas y el movimiento antiimperialista", Boletín del Exterior del Partido Comunista de Chile, n. 31, s/l, 1979.

Petras, James, y Leiva, Fernando: "Chile. The Authoritarian Transition to Electoral Politics: A critique", en Latin American Perspectives, ‥ ${ }^{15}$, 1988.

PHILP, George: "Autoritarismo militar en América Latina del Sur: Brasil, Chile, Uruguay y Argentina», Foro Internacional, n. 9 97, México, julioseptiembre 1984.

Pineda de Castro, A.: Pinochet. Verdad y ficción, Vassallo de Numbert, Madrid, 1981.

Pinochet Ugarte, Augusto: Geopolítica, Ed. Andrés Bello, Santiago de Chile, 1977.

- El día decisivo. 11 de septiembre de 1973, Ed. Andrés Bello, Santiago de Chile, 1980.

- Camino recorrido. Memorias de un soldado, Imp. del Instituto Geográfico de Chile, Santiago de Chile, 1990.

- Reflexiones en torno a una visión política de Chile, Ed. Universitaria, Santiago de Chile, 1979.

- "Política, politiquería y demagogia», Ed. Renacimiento, Santiago de Chile, 1993.

Posadas, José: El Golpe de Estado en Chile y el proceso revolucionario, Ed. Ciencia, Cultura y Política, Madrid, 1987.

Prats González, Carlos: Memorias. Testimonio de un soldado, Pehuén, Santiago de Chile, 1987.

Quiroga Zamora, Patricio: "El Prusianismo en las FF.AA. chilenas", Andes, n. 7 , Santiago de Chile, septiembre-octubre, 1984. 
Quiroga Zamora, Patricio, y Maldonado Prieto, Carlos: «El Prusianismo en las FF.AA. chilenas", Eds. Documentos, Santiago de Chile, 1988.

Rama, Carlos M.: "Las raíces fascistas del actual régimen militar chileno", Cuadernos Americanos, n. 129, México, enero-febrero 1974.

Ramirez Necochea, Hernán: Las Fuerzas Armadas y la política en Chile, Casa de Chile, México, 1984.

Rivas Sánchez, Fernando, y Reiman Weigert, Elizabeth: Las Fuerzas Armadas en Chile: un caso de penetración imperialista, Ed. Ciencias Sociales, La Habana, Cuba, 1976.

- "Las Fuerzas Armadas de Chile, un caso de penetración imperialista", Ediciones 75, México, 1976.

Rojas, M. Eugenia: Represión política en Chile. Los hechos, IEPALA, Madrid, 1988.

RoJas, Robinson: Éstos mataron a Allende, Ed. Martínez Roca, Barcelona, 1974.

Rosas, María Eugenia: «Represión política en Chile: Ios hechos», lepala, Madrid, 1988.

Rosen Kranz, Hernán: "Actitudes norteamerianas hacia la Junta Militar chilena: continuidad y cambio 1973-1978», Foro Internacional, n. 83, México, julio-septiembre 1981.

Santillana, Pablo: "Análisis de un año de gobierno militar», Prensa Latinoamericana, Buenos Aires, 1974.

Sohr, Raúl: Para entender a los militares, Ed. Melquiades, Santiago de Chile, 1989.

Subercaseaux S., Bernardo: «Diego Portales y la Junta Militar chilena. Singularidad histórica e interpretación retórica", Cuadernos Americanos, n. 216 , enero-febrero 1978.

TAufic, Camilo: Chile en la hoguera. Crónica de la represión militar, Corregidor, Buenos Aires, Argentina, 1974.

TAPIA VALDÉs, Jorge: Estrategocracia. El gobierno de los Generales, Eds. del Ornitorrinco, Santiago de Chile, 1986.

TARR, Terence: Military Intervention and Civilian Reaction in Chile 19241936, University of Florida, 1960. 
TARUD SIWAI, Rafael: Vivimos la dictadura de la maledicencia y la calumnia, $s / e, s / l$ y $s / f$.

Terrero, Patricia: «El discurso público de Pinochet de Giselle Munizaga», Ruta Cívica y Utopía, n. 12, 1985.

Timossı, Jorge: Grandes alamedas. El combate del Presidente Allende, Ed. de Ciencias Sociales, La Habana, Cuba, 1974.

Toro Dávila, Agustín: Síntesis histórico-militar de Chile, Ed. Universitaria, Santiago de Chile, 1977.

URIBE, Armando: El Libro Negro de la intervención norteamericana en Chile, Siglo XXI, México, 1974.

ValenzUela, Arturo: "Eight years of military Rule in Chile", Current History, n.. 81, Philadelphia, febrero 1982.

Valenzuela, Arturo, y Valenzuela, Samuel: Military Rule in Chile. Dictatorship and Oppositions, John Hopkins University Press, Baltimore and London, 1986.

VARAS, Augusto: «Fuerzas Armadas y gobierno militar. Corporatización y politización castrense ", Revista Mexicana de Sociología, n. ${ }^{\circ} 44$, abriljunio 1982.

- Los militares en el poder. Régimen y gobierno, FLACSO-PEHUEN, Santiago de Chile, 1977.

- Militarization and the International Arms Race in Latin America, Westview Press, FLACSO, Boulder, Colorado, 1985.

Varas, Augusto, y Aguero, Felipe: El proyecto político militar, flACSO, Santiago de Chile, 1984.

VARAS, Augusto, y otros: Chile, democracia y Fuerzas Armadas, FLACSO, Santiago de Chile, 1980.

VARAS, Florencia: Gustavo Leigh. El General disidente, Ed. Aconcagua, Santiago de Chile, 1979.

VARAs, Florencia, y Vergara, J. M.: Operación Chile, Ed. Pomaire, Barcelona, 1973.

VARGas, Luis, y otros: Chile bajo la Junta. Economía y sociedad en la dictadura militar, Ed. Zero, S. A., Bilbao, 1976.

Varios Autores: Chile bajo la Junta Militar, Ed. Zero, Madrid, 1976. 
Vázouez Montalbán, Manuel: La vía chilena al Golpe de Estado, Ed. Saturno, Barcelona, 1973.

VegA, Luis: La caída de Allende. Anatomía de un golpe de Estado, La Semana Publicaciones Ltda., Jerusalén, 1983.

VERGARA, Pilar: "Las transformaciones del Estado chileno bajo el régimen militarn, Revista Mexicana de Sociología, n.o 44, México, abril-junio 1982.

Vergudo, Patricia, y Orrego, Claudio: Detenidos desaparecidos. Una herida abierta, Aconcagua, Santiago de Chile, 1980.

Vuskovic, Pedro, y otros: "Golpe de Estado en Chile", FCE, México D.F., 1975.

Wallewsteen, Peter; Galtung, Julian, y Portales, Carlos: Global Militarization, Westview Press, Boulder, Colorado, 1985.

YÁNEZ, Hugo: «Fuerzas Armadas, sectores populares y futura institucionalidad democrátican, llades, Santiago de Chile, 1985.

ZeA, Alfredo: "Chile: Crónica del miedo", Revista Qué Hacer, n. 35, 1985. 